\title{
Palliative care for chronic illness: driving change
}

\author{
Graeme Rocker MHSc DM, James Downar MDCM MHSc, R. Sean Morrison MD
}

$\mathrm{I}$ n its 2015 Quality of Death Index report, the Economist Intelligence Unit ranked Canada 11th in overall quality of death and 18 th in availability of palliative care services. ${ }^{1}$ For efforts to develop and promote palliative care, Canada scored 3 out of 5, putting us behind Mongolia and Panama. Recent international publications ${ }^{2-4}$ and reports from Canada ${ }^{5}$ attest to the need to enhance care for people living with late-stage serious illness. In Canada, some 250000 people die each year, mostly from causes unrelated to cancer. As modern medicine has turned previously rapidly fatal illnesses into chronic diseases, most Canadians will live for many years with the symptom burden of one or more serious illnesses, functional or cognitive impairment, and dependence on care from family or society. The earlier model of palliative care that focused on specialists delivering services in the last three to six months of life is inadequate and must adapt. As of 2015, the Canadian Society of Palliative Care Physicians had fewer than 500 members. ${ }^{6}$ Palliative care in Canada is currently wrestling with workforce shortages and a need to redefine its role in the face of changing demographics and new challenges presented by legislation for assisted dying.

In this article, we focus on potential improvements to palliative care outside of cancer. We analyze evidence from both clinical initiatives and promising educational approaches that could help the development of more effective and accessible palliative care for Canadians living with chronic illness. We draw on examples both from Canada and abroad.

\section{How do Canadian palliative care services currently perform?}

Canadian palliative care in the setting of chronic illness remains relatively underdeveloped. According to two reports from the Canadian Institute for Health Information from 2007 and 2011, noncancer illnesses accounted for more than two-thirds of all deaths in Canadian provinces. ${ }^{7,8}$ Other studies have noted that only
$20 \%-30 \%$ of patients referred for consultation and admission to a palliative care unit had noncancer illness. ${ }^{9,10}$ When patients without cancer are admitted to a palliative care unit, they are typically closer to death and have a lower functional status than those with cancer. ${ }^{9}$ Population-based data suggest that Canadians dying of cancer are 5 times more likely to receive palliative care in hospital than patients dying of organ failure, and 10 times more likely than patients dying with a frailty trajectory. ${ }^{7}$ Patients dying with a frailty trajectory are almost as likely to receive inpatient palliative care as those who experience "sudden death."8

Although hospice programs and palliative care units aim to provide comprehensive support for all needs that arise in late stages of illness, technological expertise may be limited to pain control. Palliative care units rarely offer important symptomatic therapies for noncancer illness, such as noninvasive ventilation to palliate dyspnea in advanced lung disease, ${ }^{11}$ parenteral diuretics or inotrope therapy for end-stage congestive heart failure or peritoneal dialysis for symptom relief in patients dying with end-stage renal disease.

A recent international retrospective study found that Canada relies on acute hospital settings for end-of-life care more than any of the seven Western countries studied. ${ }^{12}$ Although the study was

\section{KEY POINTS}

- Most Canadians will live for years at the end of life with the symptom burdens and care requirements of one or more serious illnesses.

- Universal access to high-quality palliative care in Canada cannot be achieved if we follow the current model that equates palliative care with supportive care provided only in the last three to six months of life.

- Effective new models of palliative care - particularly those that focus on delivery of care in community settings, are team-based and are geared toward symptom management rather than requiring a particular diagnosis - should be adapted and extended more widely in Canada.

- New initiatives in residency and continuing medical education are needed to enhance the skills of the existing workforce (within primary care, internal medicine, subspecialities and paramedical professions).

- Campaigns to increase public and professional awareness are needed both to drive essential research and policy-making and to address misperceptions that equate palliative care with "end-of-life" care. 
limited to patients older than 65 years who died of cancer, it is still noteworthy that $52 \%$ of 20818 Canadian decedents died in hospital, at a mean per capita cost in the last 180 days of life of US\$21 840. Comparative figures for England were $42 \%$ of decedents and US $\$ 9342$, respectively.

\section{Why doesn't the cancer-derived model of palliative care work well for patients with other illnesses?}
A 2014 report from the Ontario Ministry of Health and Long-Term Care confirmed that most palliative care units and many palliative care ser- vices in Canada require an estimated time to death of less than three months for patients to qualify for enrolment or admission. ${ }^{5}$ However, as noted in a carefully conducted representative mortality followback survey of next of kin in the United States, patients with serious noncancer ill- ness were more likely than those with cancer to experience substantial functional impairment more than a year before death. ${ }^{13}$
In Table 1, we build on a clinical review from 2005 that highlighted the differing disease trajec- tories and implications for care ${ }^{14}$ and outline the differences between patients with cancer, organ failure and frailty in terms of prognostication and perceptions of need for palliative care.

\section{What initiatives have been effective in improving palliative care services?}

\section{Anticipating end-of-life needs in primary care}

In 2012, Scotland funded two initiatives to bolster palliative care by helping primary care physicians to better anticipate patients' needs for endof-life care. The Palliative Care Directed Enhanced Services and the Key Information Summary have formed part of a plan to extend generalist palliative care to all Scottish residents who might benefit and, for those with advanced illness, to provide care earlier rather than later.

The Key Information Summary was introduced to all general practices in 2013; it is a shareable electronic record of the most important components of a patient's care (including diagnosis, medications, carers and next of kin, understanding, function and cognition, and preferences regarding resuscitation and place of care). The summary is available to community teams, secondary care, the general practice's out-of-hours service, the ambulance service, hospital pharmacies and some hospices.

In a recent evaluation of 605 patients who died in 2014 in nine diverse practices, ${ }^{15}$ the proportion of patients identified for a Key Information Sum-

Table 1: Differences between end-of-life care for cancer, organ failure and frailty ${ }^{14}$

\begin{tabular}{|c|c|c|c|}
\hline Characteristic & Cancer & Organ failure & Frailty \\
\hline Trajectory & Progressive, accelerating deterioration & $\begin{array}{l}\text { Unpredictable, with exacerbations and } \\
\text { recoveries }\end{array}$ & $\begin{array}{l}\text { Slow, progressive deterioration; } \\
\text { sudden changes rare }\end{array}$ \\
\hline Treatment & $\begin{array}{l}\text { Curative/life-prolonging therapy often } \\
\text { stopped at the time of transition to } \\
\text { palliative care }\end{array}$ & $\begin{array}{l}\text { Disease-modifying therapies provide } \\
\text { symptom control; usually continued } \\
\text { even for palliation }\end{array}$ & $\begin{array}{l}\text { No effective disease-modifying } \\
\text { therapies; treatment primarily } \\
\text { supportive }\end{array}$ \\
\hline Prognostication & $\begin{array}{l}\text { Well-recognized syndromes or } \\
\text { functional decline associated with } \\
\text { prognosis }<6 \text { mo }\end{array}$ & $\begin{array}{l}\text { Prognostication challenging, especially } \\
\text { beyond } 3 \text { mo; patients with "end- } \\
\text { stage" disease can survive for years on } \\
\text { life-sustaining therapies (e.g., dialysis) }\end{array}$ & $\begin{array}{l}\text { Prognostication challenging; no } \\
\text { reliable models for identifying final } \\
\text { months }\end{array}$ \\
\hline Needs/concerns & $\begin{array}{l}\text { Pain/symptom control; fear of death; } \\
\text { social and physical supports typically } \\
\text { needed only in final weeks or months }\end{array}$ & $\begin{array}{l}\text { Symptom control; decisions about } \\
\text { life-sustaining therapies for organ } \\
\text { failure (e.g., ventilation, dialysis, organ } \\
\text { transplant); needs for social and } \\
\text { physical supports often long standing } \\
\text { and may exceed symptom burden }\end{array}$ & $\begin{array}{l}\text { Functional decline, cognitive } \\
\text { impairment greater concerns than fear } \\
\text { of dying; symptoms variable }\end{array}$ \\
\hline $\begin{array}{l}\text { Typical patient } \\
\text { demographics }\end{array}$ & Age $45-75$ yr; often family caregiver & $\begin{array}{l}\text { Age } 70-85 \text { yr; partner more likely to } \\
\text { be deceased, or elderly and unable to } \\
\text { provide support }\end{array}$ & $\begin{array}{l}\text { Age } \geq 75 \text { yr; partner more likely to be } \\
\text { deceased, or elderly and unable to } \\
\text { provide support }\end{array}$ \\
\hline $\begin{array}{l}\text { Typical patient } \\
\text { location; composition } \\
\text { of medical team }\end{array}$ & $\begin{array}{l}\text { Community dwelling, with increasing } \\
\text { visits to acute medical facility; care } \\
\text { provided by single or multiple } \\
\text { specialists (e.g., oncologist, with } \\
\text { transition to palliative care specialist) } \\
\text { associated with tertiary care facility }\end{array}$ & $\begin{array}{l}\text { Community dwelling, with frequent } \\
\text { visits to acute medical facility; care } \\
\text { provided by multiple specialists or } \\
\text { coordinated by general practitioner } \\
\text { and a specialist; focus of care may be } \\
\text { in tertiary care centre or primary care } \\
\text { setting }\end{array}$ & $\begin{array}{l}\text { Often residents of assisted-living or } \\
\text { long-term care facilities; less frequent } \\
\text { visits to acute medical facility; care } \\
\text { generally provided by general } \\
\text { practitioner based at assisted-living or } \\
\text { long-term care facility; less affiliation } \\
\text { with tertiary care centre }\end{array}$ \\
\hline $\begin{array}{l}\text { Professional/societal } \\
\text { view of illness }\end{array}$ & Clearly viewed as life-limiting & $\begin{array}{l}\text { Often viewed as chronic illness rather } \\
\text { than life-limiting }\end{array}$ & Often not viewed as an illness \\
\hline
\end{tabular}


mary was lower among patients dying with dementia or frailty $(66 \%$ [125/189]) and those dying from organ failure (41\% [83/204]) than among patients with cancer (74\% [158/212]). Although these are areas for improvement, in a comparison of 2014 and 2011 data, patients with dementia and frailty were more likely to be identified for palliative care in 2014 (35\% v. 20\%) and were identified earlier (10 wk v. 2 wk before death). ${ }^{15}$

General practitioners interviewed as part of the evaluation felt that the Key Information Summary was valuable not simply for identifying patients suitable for palliative care, but for advance care planning as part of a more generic goals-ofcare rather than diagnosis-driven approach. ${ }^{15}$

To identify patients for a Key Information Summary, general practitioners use the validated Supportive and Palliative Care Indicators Tool (SPICT, www.spict.org.uk). The tool is used broadly now within the United Kingdom. Recently it was refined and evaluated in a study of 130 unplanned hospital admissions for chronic illness in Scotland,${ }^{16}$ where the tool "helped identify patients with multiple unmet needs who would benefit from earlier, holistic needs assessment, a review of care goals, and anticipatory care planning."16

A funded, sharable electronic record of key information for all general practices, supported by a validated tool to identify patients who would benefit from early palliative care, would go a long way to transforming both anticipation of needs for end-of-life care and continuity of care in the Canadian context.

\section{Managing symptoms in the community}

In Cambridge, UK, the Breathlessness Intervention Service takes a symptom-based approach to home-based care of dyspnea as a manifestation of any diagnosis, whether cancer, cardiopulmonary or neurologic disease. The initiative stands apart as a multidisciplinary complex intervention that follows a palliative care approach. It uses evidence-based nonpharmacologic and pharmacologic interventions to support patients with advanced disease in managing their breathlessness. In the most recent evaluation of the service (a mixed-methods randomized controlled trial involving 87 patients), patients with noncancer conditions and their carers described a range of positive impacts, including reduced fear, anxiety, worry and feelings of panic. ${ }^{17}$ The Breathlessness Intervention Service was shown to be effective and cost-effective for patients with advanced cancer and their carers, and to hold promise for those with advanced nonmalignant conditions. ${ }^{17}$

A recent large retrospective study of the impact of specialist palliative care teams providing services in patients' homes in Ontario reported a reduction of about 50\% in hospital deaths at the end of life compared with non-team-based usual care. ${ }^{18}$ The community-based palliative care teams managed patients' symptoms, provided education and care, coordinated services and were available 24 hours a day. Although many patients in the study had cancer, the intervention could be generalized to home-based care of patients without cancer.

The INSPIRED COPD Outreach Program is an evidence-based facility-to-community clinical initiative started in Halifax in 2010 that is designed to improve the care of patients with moderate to severe chronic obstructive pulmonary disease. About 500 patients with advanced COPD have been enrolled to date. Using a multicomponent intervention during four home visits, the program focuses on improving care transitions, enabling effective self-management and discussing advance care planning. Similar to the Key Information Summary initiative in Scotland, ${ }^{15}$ summarized documentation (concerning the patient's choices for cardiopulmonary resuscitation, bilevel positive airway pressure and intubation) are uploaded to the database of the local emergency health services.

A recent economic analysis of the costs and outcomes of the INSPIRED program estimated that only 26 patients need to complete the program to avert an estimated $\$ 100000$ in hospital-based costs..$^{19}$ Of 84 patients enrolled in the program who died from 2011 to 2015, 32 (38\%) were supported in dying at home through effective advance care planning (current completion rate of written personal directives is $>80 \%) .{ }^{20}$ A mixed-method evaluation of the INSPIRED program confirmed high patient satisfaction and the program's continued impact in reducing emergency department visits, hospital admissions and days in hospital by more than $60 \%$ among participants. ${ }^{21}$

The Canadian Foundation for Healthcare Improvement has supported the spread of the INSPIRED program to 19 teams representing 78 health care sites (academic, regional and community based) across all 10 provinces..$^{21}$ Results to date within this national collaborative (about 1000 additional patients enrolled) are similarly promising. For estimated cost savings if the program were to be scaled up and spread across Nova Scotia, see Box 1.

Box 1: Potential cost savings of the INSPIRED COPD Outreach Program A RiskAnalytica report 22 estimated that, were the INSPIRED COPD Outreach Program to be scaled up and spread across Nova Scotia for appropriate patients, the net cost aversion over the next five years would be about $\$ 20$ million, and $\$ 688$ million nationally. The latter would offset much of the annual cost of hospital admissions due to COPD across Canada ( $\$ 750$ million in $2008^{23}$ ).

For further information about the Canadian Foundation for Healthcare Improvement's approach to potential scale up and spread of new initiatives go to www.cfhi-fcass.ca/WhatWeDo/inspired-approaches-to-copd 
Through the Canadian Partnership Against Cancer's Paramedics Providing Palliative Care at Home Program, all 1100 paramedics across the provinces of Nova Scotia and Prince Edward Island received a clinical practice guideline by the end of June 2015 on providing care in line with palliative goals for eligible patients, including remaining at home, plus additional training through Learning Essential Approaches to Palliative and End-of-Life Care (LEAP Paramedic) courses. In the first year of operation in Nova Scotia, paramedics answered more than 300 requests for palliative support, keeping 55\% of the patients at home. On Prince Edward Island, 59 calls for palliative support were received in the first 170 days, and $43 \%$ of the patients were able to remain at home. About $25 \%$ of the patients had chronic illness. Future evaluation of the program will include the impact on paramedics, patients and family members, and the health care system and should be complete by January 2017 (Dr. Alix Carter, Dalhousie University, Halifax: personal communication, 2016).

\section{Considering frailty first}

The Palliative and Therapeutic Harmonization (PATH) model in Halifax places frailty at the forefront of medical and surgical decision-making, helping older people and their families understand their health status and guiding them through the process of making health care decisions that protect their best interests and quality of life. In an early analysis of decisions for the first 150 patients who completed the PATH program, those with a greater degree of frailty (odds ratio [OR] 3.41) or more advanced dementia (OR 1.66) were more likely than patients at less severe stages of illness to choose less aggressive treatment options than scheduled medical or surgical interventions. ${ }^{24}$ The program currently has 635 patients enrolled and continues to have rates of avoiding major interventions of 33\%$54 \%$ depending on level of frailty, with cost savings for the full cohort of about $\$ 4.5$ million (Dr. Paige Moorhouse, Dalhousie University, Halifax: personal communication, 2016).

\section{Decoupling palliative care from end-of-life care}

Not all people who need palliative care are facing imminent death. Many patients with end-stage organ failure are justified in thinking that "life-sustaining therapy" could help them during an exacerbation of their illness (e.g., noninvasive ventilation for COPD, or use of inotropes for heart failure). Recent qualitative research suggests some ambivalence by patients and caregivers about the term "palliative care." 25 The success of promoting a more positive concept is perhaps best evidenced by efforts based on public opinion research of the
US Center to Advance Palliative Care to redefine palliative care as an added layer of support during care of any serious illness. ${ }^{26}$ This public opinion research has been one of the key drivers of enhanced access (often concurrently with active treatment) and acceptance of palliative care. For example, in the decade before 2014, 1000 new hospital-based palliative care teams were created. As of 2014, palliative care was the fastest growing specialty in the US, ${ }^{27}$ and according to a 2015 report, more than $70 \%$ of hospitals with at least 50 beds had palliative care teams. ${ }^{28}$

Given the changing demographics of our population, Canada should be heading in the same direction, with backing from innovative public awareness campaigns and similarly accessible resources as those outlined in Appendix 1 (available at www.cmaj.ca/lookup/ suppl/doi:10.1503/cmaj.151454/-/DC1).

\section{How should we educate providers of palliative care in Canada?}

The new models we have described expand the traditional remit of palliative care and show the benefit of team-based care in the management of chronic illness. These programs retrain existing providers and thus reduce reliance on the limited workforce of palliative care specialists. The core components include training of existing providers in core palliative care knowledge and skills, systematic and routinized symptom assessment and advance care planning, care coordination, and support from palliative care specialists when appropriate. In Canada, earlier provision of quality palliative care could be achieved by extending less costly community-based approaches, combining the skills of primary and specialist care to provide coordinated care that is aligned with the preferences of patients and their families.

The Royal College of Physicians and Surgeons of Canada recently approved a two-year subspecialty training program in palliative medicine to replace the 12-month residency program that was conjointly accredited by the College of Family Physicians of Canada. This program will go some way to addressing gaps in palliative care for noncancer illness, which will be the main focus of the additional year. The cold reality of insufficient numbers of palliative medicine specialists in Can$\operatorname{ada}^{6}$ and of education gaps reported by internal medicine residents in a national survey ${ }^{29}$ supports the proposal from the Center to Advance Palliative Care that all clinicians who care for people with serious illnesses have training in the core knowledge and skills of palliative care. ${ }^{30}$ The completion of the centre's curriculum by more than 8500 clini- 
cians $(75 \%$ of whom were from specialties outside of palliative care) suggests widespread professional support. ${ }^{30}$ The Royal College of Physicians and Surgeons of Canada and the College of Family Physicians of Canada should add mandatory palliative medicine rotations to the specific training requirements for residency programs in family medicine, emergency medicine and internal medicine, and in all of the subspecialty programs. This training should encompass the core triad of palliative care - pain and symptom management (including psychological and spiritual distress), communication skills, and care coordination for patients with complex illnesses and their families. Other health professionals (e.g., nurses, social workers and home health workers) will need additional training to improve palliative care skills in, for example, long-term care settings where much palliative care is provided. ${ }^{31}$

Several resources exist to increase core knowledge of palliative medicine for physicians in training in Canada (e.g., for family medicine trainees, a year of added competence in Palliative Care). Other examples, for clinicians in practice, include the Learning Essential Approaches to Palliative and End-of-Life Care courses offered by Pallium Canada (www.pallium.ca) and Web-based resources offered through the Canadian Virtual Hospice (www.virtualhospice.ca). In the US, resources such as the Center to Advance Palliative Care's Web-based training modules in the core principles of palliative care (www.capc.org), Vital Talk's curriculum on communication training (www.vitaltalk.org) and the End-of-Life Nursing Education Consortium (www.aacn.nche.edu/ elnec) are available to Canadian physicians and nurses.

\section{What research is needed?}

In Appendix 2 (available at www.cmaj.ca/lookup/ suppl/doi:10.1503/cmaj.151454/-/DC1), we summarize some recent research and related initiatives that extend our discussion. ${ }^{9,32-37}$ Palliative care researchers face unique challenges in study design and analysis that require complex solutions (Box 2). In 2011, the Parliamentary Committee on Palliative and Compassionate Care recommended the re-establishment of a national Palliative Care Secretariat, with "adequate funding to conduct and support research." ${ }^{38}$ Coordinating efforts nationwide through a trials group that could conduct large-scale and timely studies as well as expanding our understanding of patient and caregiver experience through qualitative methodology would increase both the quality and the impact of Canadian research in palliative care. In addition, new paradigms and related innovation will require increasing familiarity with alternatives to conventional randomized controlled trials, ${ }^{39}$ as well as quality improvement strategies and methodologies that might be more appropriate for the evaluation and for the scale up and spread of successful models. Expertise in scale up and spread is the remit of organizations such as the Canadian Foundation for Healthcare Improvement (www.cfhifcass.ca), which promotes the Triple Aim concept of "better care, better health, better value."

\section{Driving change in Canada}

There is much to do to improve on Canada's international standing in palliative care. Overcoming traditional barriers will not be easy. We will need to move away from the paradigm that limits palliative care to the end of life and excludes patients who are receiving ongoing medical therapy. We will need fundamental innovative change to high-level policies and funding models.

Nevertheless, our goals should not be to impress expert panels or the Economist Intelligence Unit, but rather to meet the needs of the 250000 Canadians who will die this year and the tens of thousands more who are living with serious illness and deserve high-quality, accessible palliative care.

Box 2: Study design and analysis issues relevant to palliative care research

\section{Design issues}

- Traditionally, research in pain and other symptoms has relied upon patient self-report as the gold standard for assessment. For patients with cognitive impairment, such assessment may be impractical or impossible and require reliable means of assessment through behavioural observation or the use of proxies.

- Patients may have multiple symptoms that interact, and it can be difficult to distinguish between symptoms caused by illness and those due to treatments. Instruments are required to assess a wide constellation of symptoms and multiple dimensions within each symptom.

- Although some research questions in palliative care may be addressed using the gold standard of clinical research — randomized controlled trials (RCTs) - many others may be feasibly or more appropriately addressed in studies using observational or quasi-experimental designs. ${ }^{23}$ Thus, improvements in care may require careful and innovative use of nonrandomized and sometimes uncontrolled settings (Appendix 1, available at www.cmaj.ca/ lookup/suppl/doi:10.1503/cmaj.151454/-/DC1), which may have greater external validity (albeit lesser internal validity) than traditional RCTs. ${ }^{23}$

\section{Analytic issues}

- Dealing with missing data (e.g., death or inability to report symptoms, concerns or attitudes because illness, confusion, weakness or loss of consciousness) is challenging. Sophisticated research methods to deal with nonrandom missing data have been developed but are not widely used yet.

- Observational and quasi-experimental designs require sophisticated and sometimes troublesome analytical techniques to strengthen any inferences that can be made (e.g., propensity score method ${ }^{18}$ to reduce selection bias, instrumental variable techniques).

More information is available from the US National Palliative Care Research Center (http://npcrc.org/content/45/Research-Priorities-in-Geriatric-PalliativeCare.aspx). 


\section{References}

1. The 2015 Quality of Death Index: ranking palliative care across the world; The Economist Intelligence Unit; 2015.

2. Kelley AS, Morrison RS. Palliative care for the seriously ill. N Engl J Med 2015;373:747-55.

3. Graham J. IOM report calls for transformation of end-of-life care. JAMA 2014;312:1845-7.

4. Moffat K, Mercer SW. Challenges of managing people with multimorbidity in today's healthcare systems. BMC Fam Pract 2015;16:129.

5. Annual report 2014. Toronto: Office of the Auditor General of Ontario; 2014.

6. Human Resources Committee. Highlights from the National Palliative Medicine Survey. Surrey (BC): Canadian Society of Palliative Care Physicians; 2015. Available: www.cspcp.ca/wp-content/ uploads/2015/04/PM-Survey-Final-Report-EN.pdf (accessed 2016 July 29).

7. Health care use at the end of life in Western Canada. Ottawa: Canadian Institute for Health Information; 2007.

8. Health care use at the end of life in Atlantic Canada. Ottawa: Canadian Institute for Health Information; 2011.

9. Downar J, Chou YC, Ouellet D, et al. Survival duration among patients with a noncancer diagnosis admitted to a palliative care unit: a retrospective study. J Palliat Med 2012;15:661-6.

10. Lau F, Maida V, Downing M, et al. Use of the Palliative Performance Scale (PPS) for end-of-life prognostication in a palliative medicine consultation service. J Pain Symptom Manage 2009; 37:965-72.

11. Sinuff T, Cook DJ, Keenan SP, et al. Noninvasive ventilation for acute respiratory failure near the end of life. Crit Care Med 2008;36:789-94.

12. Bekelman JE, Halpern SD, Blankart CR, et al. Comparison of site of death, health care utilization, and hospital expenditures for patients dying with cancer in 7 developed countries. JAMA 2016;315:272-83.

13. Teno JM, Weitzen S, Fennell ML, et al. Dying trajectory in the last year of life: Does cancer trajectory fit other diseases? J Palliat Med 2001;4:457-64.

14. Murray SA, Kendall M, Boyd K, et al. Illness trajectories and palliative care. $B M J$ 2005;330:1007-11.

15. Tapsfield J, Hall C, Lunan C, et al. Many people in Scotland now benefit from anticipatory care before they die: an after death analysis and interviews with general practitioners. BMJ Support Palliat Care 2016; doi:10.1136/bmjspcare-2015-001014

16. Highet G, Crawford D, Murray SA, et al. Development and evaluation of the Supportive and Palliative Care Indicators Tool (SPICT): a mixed-methods study. BMJ Support Palliat Care 2014; 4:285-90.

17. Farquhar MC, Prevost AT, McCrone P, et al. The clinical and cost effectiveness of a Breathlessness Intervention Service for patients with advanced non-malignant disease and their informal carers: mixed findings of a mixed method randomised controlled trial. Trials 2016;17:185

18. Seow H, Brazil K, Sussman J, et al. Impact of community based, specialist palliative care teams on hospitalisations and emergency department visits late in life and hospital deaths: a pooled analysis. BMJ 2014;348:g3496.

19. Rocker GM, Verma JY, Demmons J, et al. Number needed to.. Save? Clin Invest Med 2015;38:E11-4.

20. Blackman R, Demmons J, Gillis D, et al. Dying at home from COPD: Feasible or fantasy? [abstract]. Chest 2016;150 (4 S):951A doi:10.1016/j.chest.2016.08.1053

21. Rocker GM, Verma JY. 'INSPIRED' COPD Outreach Program ${ }^{\mathrm{TM}}$ doing the right things right. Clin Invest Med 2014;37:E311-9.

22. Smetanin P, McNeil D, Burger C. Modelling the INSPIRED COPD Outreach Program ${ }^{T M}$ : national and provincial analysis final report. RiskAnalytica; 2016. Available: www.cfhi-fcass.ca/ sf-docs/default-source/documents/inspired/inspired-riskanalytica -e.pdf?sfvrsn=2 (accessed 2016 Aug 4).

23. Mittmann N, Kuramoto L, Seung SJ, et al. The cost of moderate and severe COPD exacerbations to the Canadian healthcare system. Respir Med 2008;102:413-21.

24. Moorhouse P, Mallery LH. Palliative and Therapeutic Harmonization: a model for appropriate decision-making in frail older adults. J Am Geriatr Soc 2012;60:2326-32.

25. Zimmermann C, Swami N, Krzyzanowska M, et al. Perceptions of palliative care among patients with advanced cancer and their caregivers. CMAJ 2016;188:E217-27.

26. 2011 public opinion research on palliative care: a report based on research by public opinion strategies. New York: Center to Advance Palliative Care; 2011. Available: https://media.capc.org /filer_public/18/ab/18ab708c-f835-4380-921d-fbf729702e36 /2011-public-opinion-research-on-palliative-care.pdf (accessed 2016 Aug. 4).

27. Hughes MT, Smith TJ. The growth of palliative care in the United States. Annu Rev Public Health 2014;35:459-75.

28. America's care of serious illness: 2015 state-by-state report card on access to palliative care in our nation's hospitals. New York: Center to Advance Palliative Care and National Palliative Care Research Center; 2015. Available: https://reportcard.capc.org/wp-content/ uploads/2015/08/CAPC-Report-Card-2015.pdf (accessed 2016 Aug. 4).

29. Schroder C, Heyland D, Jiang X, et al. Educating medical residents in end-of-life care: insights from a multicenter survey. J Palliat Med 2009;12:459-70.

30. Center to Advance Palliative Care. A thank you to the palliative care education community [blog]. Palliative in Practice; 2016 June 29. Available: https://palliativeinpractice.org/palliative-pulse/ june-2016/thank-palliative-care-education-community (accessed 2016 Aug. 5).

31. Brazil K, Brink P, Kaasalainen S, et al. Knowledge and perceived competence among nurses caring for the dying in longterm care homes. Int J Palliat Nurs 2012;18:77-83.

32. Bakitas M, Macmartin M, Trzepkowski K, et al. Palliative care consultations for heart failure patients: How many, when, and why? J Card Fail 2013;19:193-201.

33. Cook D, Swinton M, Toledo F, et al. Personalizing death in the intensive care unit: the 3 Wishes Project: a mixed-methods study. Ann Intern Med 2015;163:271-9.

34. George N, Phillips E, Zaurova M, et al. Palliative care screening and assessment in the emergency department: a systematic review. J Pain Symptom Manage 2016;51:108-19.e2.

35. Higginson IJ, Bausewein C, Reilly CC, et al. An integrated palliative and respiratory care service for patients with advanced disease and refractory breathlessness: a randomised controlled trial. Lancet Respir Med 2014;2:979-87.

36. Kimbell B, Murray SA. What is the patient experience in advanced liver disease? A scoping review of the literature. BMJ Support Palliat Care 2015;5:471-80.

37. Oliver DJ, Borasio GD, Caraceni A, et al. A consensus review on the development of palliative care for patients with chronic and progressive neurological disease. Eur J Neurol 2016;23:30-8.

38. Not to be forgotten: care of vulnerable Canadians. Ottawa: Parliamentary Committee on Palliative and Compassionate Care; 2011. Available: http://pcpcc-cpspsc.com/wp-content/uploads/2011/11/ ReportEN.pdf (accessed 2016 Aug 4).

39. Black N. Why we need observational studies to evaluate the effectiveness of health care. BMJ 1996;312:1215-8.

Competing interests: Graeme Rocker is the Medical Director of the INSPIRED COPD Outreach Program, which is funded by Capital Health (now the Nova Scotia Health Authority). He is the lead faculty of the "INSPIRED Approaches to COPD: Improving Care and Creating Value" Collaborative, which was delivered by the Canadian Foundation for Healthcare Improvement (CFHI) with funding support from Boehringer Ingelheim (Canada) Ltd; this support enabled 19 teams within the collaborative (in every Canadian province) to implement an INSPIRED-like project in their care settings. He was Clinical Improvement Advisor to CFHI from July 2013 to Dec 2015. James Downar is an advisory board member for Boehringer-Ingelheim (Canada) Ltd. No other competing interests were declared.

Affiliations: Department of Medicine (Rocker), Dalhousie University, Halifax, NS; Division of Respirology (Rocker), QEII Health Sciences Centre, Halifax, NS; Palliative Care and Critical Care (Downar), University Health Network, Toronto, Ont.; Divisions of Critical Care and Palliative Care (Downar), University of Toronto, Toronto, Ont.; National Palliative Care Research Center (Morrison), New York, NY; Hertzberg Palliative Care Institute (Morrison), Mt. Sinai School of Medicine, New York, NY; Brookdale Department of Geriatrics and Palliative Medicine (Morrison), Icahn School of Medicine at Mount Sinai, New York, NY

Contributors: All of the authors contributed substantially to the conception, analysis and interpretation of this review, revised it critically for important intellectual content, approved the final version to be published and agreed to act as guarantors of the work. 